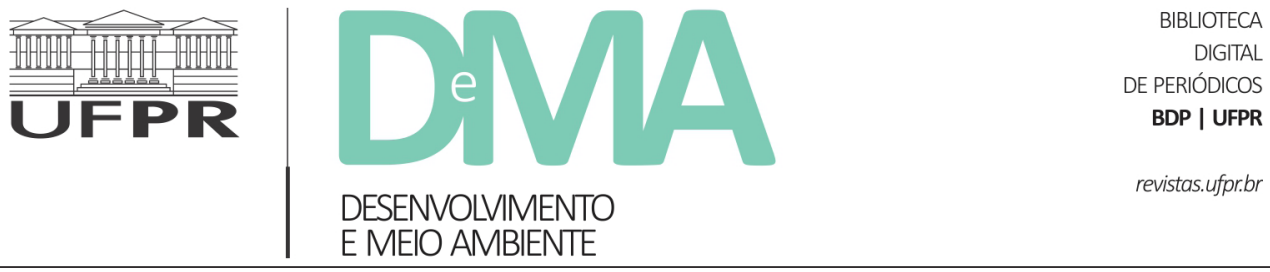

\title{
Cenário atual e perspectivas da tilapicultura no estado do Pará frente ao novo marco regulatório da atividade
}

\section{Current scenario and perspectives of tilapia farming in the Pará State in view of the new legislation of the activity} \author{
Araújo SILVA ${ }^{1}$ \\ ${ }^{1}$ Universidade Federal Rural da Amazônia (UFRA), Belém, PA, Brasil. \\ ${ }^{2}$ Universidade Federal do Pará (UFPA), Belém, PA, Brasil. \\ *E-mail de contato: leobarbosa_s@hotmail.com
}

Leonilton Rodrigues Barbosa da SILVA ${ }^{1 *}$, Marcos Ferreira BRABO ${ }^{2}$, Mayara da Costa PEREIRA ${ }^{1}$, Cyntia Meireles MARTINS ${ }^{1}$, Marcos Antônio Souza dos SANTOS ${ }^{1}$, Breno Gustavo Bezerra COSTA ${ }^{1}$, Kátia Cristina de

Artigo recebido em 14 de abril de 2020, versão final aceita em 6 de outubro de 2020, publicado em 27 de maio de 2021.

RESUMO: Um novo marco regulatório para o cultivo de espécies exóticas em empreendimentos aquícolas no estado do Pará foi estabelecido pela Resolução COEMA n 143 de 20 de dezembro de 2018. Esta norma jurídica influencia principalmente os produtores de tilápia Oreochromis spp., que desde a publicação da Lei Estadual $\mathrm{n}^{\circ} 6.713$ de 25 de janeiro de 2005 não tinham como regularizar seus empreendimentos perante os órgãos ambientais. O objetivo deste estudo foi apresentar o cenário atual da tilapicultura no território paraense, bem como discorrer sobre as modalidades de produção adotadas comercialmente e analisar suas perspectivas de regularização frente à nova legislação. Os dados relativos ao número de empreendimentos, produção e valor da produção foram obtidos junto ao IBGE. A caracterização das modalidades de produção ocorreu por meio de observações de campo e entrevistas com piscicultores em dezembro de 2019, contemplando iniciativas de produção em viveiro escavado, tanque-rede e tanque suspenso em sistema de bioflocos. As informações obtidas foram confrontadas com as exigências da nova norma jurídica e analisadas no tocante a possibilidade de regularização. Segundo dados do Censo Agropecuário 2017 havia 3.089 iniciativas de tilapicultura distribuídas em 124 municípios paraense, com a maior concentração ocorrendo nas regiões hidrográficas Tocantins-Araguaia, Amazônica e Atlântico Nordeste Ocidental, respectivamente. Constatouse que a produção de tilápia foi de 262,8 toneladas em 2018 , o que correspondeu a $2 \%$ do total estadual e um valor da produção de R \$2,5 milhões. Dentre as modalidades analisadas, apenas os tanques suspensos em sistema de bioflocos apresentavam viabilidade técnica para atendimento das exigências do novo marco 
regulatório. Concluiu-se que a tilapicultura é incipiente em volume e técnicas de produção e que o novo marco regulatório diverge das normativas empregadas em estados contidos na mesma realidade hidrográfica.

Palavras-chave: piscicultura; Pará; espécie exótica; legislação; Oreochromis niloticus.

ABSTRACT: New legislation for the use of exotic species in aquaculture in the Pará State was established by COEMA Resolution $n^{\circ} 143$ of December 20,2018. This legal rule influences mainly the producers of tilapia Oreochromis spp., which since the publication of the State Law $n^{\circ}$ 6,713 of January 25, 2005, could not regularize their initiatives before the environmental agencies. The objective of this study was to present the current scenario of tilapia farming in the Pará State, as well as to discuss the production modalities adopted commercially and to analyze their prospects of regularization because of the new legislation. Data on the number of tilápia farming, production, and production value were obtained from IBGE. The characterization of the production modalities took place through field observations and interviews with fish farmers in December 2019, contemplating initiatives of farming in ponds, net cages, and suspended tanks in the biofloc system. The information obtained was confronted with the requirements of the new legislation and analyzed the possibility of regularization. According to data from the 2017 Census Agriculture, there 3,089 tilapia farming initiatives distributed in 124 cities from Pará, with the largest concentration occurring in the Tocantins-Araguaia, Amazônica, and Atlântico Nordeste Occidental hydrographic regions, respectively. It was found that the production of tilapia in the Pará State was 262.8 tons in 2018, which corresponded to $2 \%$ of the state total and a production value of R \$ 2.5 million. Among the analyzed modalities, only the suspended tanks in the biofloc system presented technical viability to meet the requirements of the new legislation. It was concluded that tilapia farming is incipient in amount and production techniques and that the new legislation differs from the regulations used in states contained in the same hydrographic reality.

Keywords: fish farming; Pará state; exotic species; legislation; Oreochromis niloticus.

\section{Introdução}

A produção mundial de pescado foi de 172,6 milhões de toneladas em 2017, com 46,5\% deste total sendo oriundo da aquicultura. Desta modalidade agropecuária, a piscicultura continental é o ramo mais desenvolvido no planeta e a tilápia do Nilo Oreochromis niloticus (Linnaeus, 1758) foi a terceira espécie mais produzida neste ano, com 4,1 milhões de toneladas, atrás apenas da carpa capim Ctenopharyngodon idellus (Valenciennes, 1844) e da carpa prateada Hypophthalmichthys molitrix (Valenciennes, 1844). Os países que se sobressaíram neste cenário foram: a China, a Indonésia, o Egito e o Brasil (FAO, 2019).
No Brasil, a tilápia é a principal espécie da piscicultura continental e responde pela parcela de 281,2 mil toneladas, o que representa $49,9 \%$ do total da aquicultura nacional. As regiões Sul e Sudeste são os principais produtores de tilápia no país e são impulsionadas pelos estados do Paraná e São Paulo, os quais respondem por 92,3 e 42,7 mil toneladas, respectivamente, tornando-os maiores produtores da espécie. No caso do Norte, a região apresenta menor expressão na produção de tilápia do país, e dentre os sete estados que compõem a região, Rondônia, Amazonas e Roraima não possuem comercialização declarada (SIDRA, 2019; PEIXE-BR, 2020).

O estado do Pará detém mais da metade da produção de tilápia apresentada na região Norte, tornando-o principal produtor tanto em volume 
produzido quanto em número de empreendimentos. As inciativas de produção na grande maioria exercem a atividade em regime familiar e em pequenos reservatórios hídricos, características estas que se enquadram nas diretrizes da Lei $n^{\circ} 11.326$ de 24 de julho de 2006, que estabelece a política nacional da agricultura familiar (Brasil, 2006; SIDRA 2019; Brabo et al., 2020).

A introdução da espécie no estado paraense ocorreu na década de 1970, a qual foi incentivada por mais de três décadas pelos órgãos governamentais de fomento e assistência técnica. Contudo, a partir da Lei Estadual n ${ }^{\circ} 6.713$ publicada em 25 de janeiro de 2005, o cultivo de espécies exóticas em sistemas aberto passou a ser considerado como atividade ilegal (Pará, 2005; Brabo et al., 2015; 2020; SIDRA, 2019). A falta de clareza na legislação sobre os conceitos de sistema de produção provocou interpretações divergentes e inviabilizaram a regularização junto ao órgão ambiental estadual no período de 2005 a 2018.

A edição da Resolução ${ }^{\circ} 28$ de 20 de dezembro de 2018 do Conselho Estadual de Meio Ambiente (COEMA) foi o marco mais recente para a piscicultura no estado e possibilitou a regularização de empreendimentos de tilapicultura exclusivamente em sistemas fechado de produção (Pará, 2006; 2018). Entre as justificativas para o ato está o princípio da precaução, o qual visa impedir a dispersão da espécie em cursos d'água naturais do território paraense, dado os impactos ambientais que poderiam ser gerados pelo estabelecimento de sua população, como diminuição de estoques pesqueiros e perda da biodiversidade (Attayde et al., 2011; Bittencourt et al., 2014; Brabo et al., 2015).

Neste contexto, cabe enfatizar que mesmo de forma irregular, diversos piscicultores continua- ram a investir na produção de tilápia no estado do Pará, principalmente pela rentabilidade superior em tanques-rede em relação a espécies nativas e sua eficiência como peixe forrageiro vivo para carnívoros (Brabo et al., 2016a; 2017; 2020). Contudo, pouco se conhece sobre a atividade no estado, sobretudo relacionada aos aspectos legais, uma vez que a grande maioria das informações são genéricas e subproduto de estudos mais amplo sobre a piscicultura no estado (De-Carvalho et al., 2013; O' de Almeida-Junior \& Souza, 2013; Oliveira et al., 2014; Brabo et al., 2016c; Brabo et al., 2016d).

A edição do novo marco regulatório desperta a necessidade em trazer à discussão os elos que envolvem a cadeia da tilapicultura no estado, enaltecendo aspectos que podem servir de ferramenta para a tomada de decisão dos órgãos de governo e futuros investidores. Portanto, o objetivo deste estudo foi apresentar o cenário atual da tilapicultura no estado do Pará, bem como discorrer sobre as modalidades de produção adotadas comercialmente e analisar suas perspectivas de regularização frente ao novo marco regulatório da atividade.

\section{Evolução do marco regulatório da aquicultura com espécies exóticas no Brasil e no estado do Pará}

Em 1992, o Brasil assinou um tratado da Organização das Nações Unidas (ONU) denominado Convenção sobre Diversidade Biológica (CDB), que se constitui em um dos mais importantes instrumentos internacionais relacionados ao meio ambiente e prevê a conservação da biodiversidade, seu uso sustentável e a repartição justa e equitativa dos benefícios provenientes da utilização dos recursos 
genéticos. No território nacional, a regulamentação deste ato ocorreu por meio do Decreto Federal ${ }^{\circ}$ 2.519 de 16 de março de 1998 (Brasil, 1998a).

Um dos efeitos desta legislação foi a edição da Portaria do Instituto Brasileiro de Meio Ambiente e Recursos Naturais Renováveis (IBAMA) n 145 de 29 de outubro 1998, que estabelece normas para a introdução, reintrodução e transferência de peixes, crustáceos, moluscos e macrófitas aquáticas para fins de aquicultura. Esta norma jurídica definiu o termo "espécie exótica" como àquela de origem e ocorrência natural somente em águas de outros países, quer tenha ou não já sido introduzida em águas brasileiras. Estabeleceu, ainda, a denominação "espécie alóctone" para àquelas de origem e ocorrência natural em águas de Unidade Geográfica Referencial (UGR) que não a considerada (Brasil, 1998b).

Neste contexto, UGR corresponde à área abrangida por uma bacia hidrográfica ou, no caso de águas marinhas e estuarinas, faixas de águas litorâneas compreendidas entre dois pontos da costa brasileira. Esta definição serviu de parâmetro para elaboração dos anexos da portaria, que listaram as espécies exóticas e alóctones detectadas em todas as bacias hidrográficas brasileiras, constatações que inclusive foram atualizadas pela Portaria IBAMA ${ }^{\circ}$ 27 de 22 de maio de 2003 (Brasil, 1998b; 2003a).

A norma supracitada balizou a edição do Decreto Federal n ${ }^{\circ} 4.895$ de 25 de novembro de 2003, que dispõe sobre a autorização de uso de espaços físicos de corpos d'água de domínio da União para fins de aquicultura e estabelece a seguinte condição:

Art. $8^{\circ}: \mathrm{Na}$ exploração da aquicultura em águas continentais e marinhas, será permitida a utilização de espécies autóctones ou de espécies alóctones e exóticas que já estejam comprovadamente estabelecidas no ambiente aquático, onde se localizará o empreendimento (Brasil, 2003b).

No cenário estadual, o Pará editou uma legislação mais restritiva do que as apresentadas no âmbito federal, a qual foi evidenciada pela Lei ${ }^{\circ} 6.713$ de 25 de janeiro de 2005 , que dispõe sobre sua política pesqueira e aquícola e em seu Artigo $29^{\circ}$ considera o cultivo de espécies exóticas em sistemas aberto como atividade ilegal. Contudo, a lei supracitada e o Decreto ${ }^{\circ} 2.020$ de 25 de janeiro de 2006, que a regulamenta, não definiram o referido sistema, inviabilizando a regularização de iniciativas com essas espécies (Pará, 2005; 2006).

$\mathrm{Na}$ esfera federal, a Resolução do Conselho Nacional do Meio Ambiente (CONAMA) n ${ }^{\circ} 413$ de 26 de junho de 2009, que estabelece critérios para o licenciamento da aquicultura no território nacional, trouxe maior clareza ao assunto, a exemplo dos artigos abaixo:

Art. $3^{\circ}$ - III: Espécie alóctone ou exótica: espécie que não ocorre ou não ocorreu naturalmente na Unidade Geográfica Referencial (UGR) considerada.

Art. 19०: O órgão ambiental licenciador poderá exigir do empreendedor a adoção de medidas econômica e tecnologicamente viáveis de prevenção e controle de fuga das espécies cultivadas, devendo estas medidas constarem obrigatoriamente como condicionantes das licenças emitidas (Brasil, 2009a).

O Anexo III desta resolução possui um item a ser preenchido no cadastro do empreendimento aquícola, que exige as informações mínimas a serem apresentadas nas solicitações de licenciamento ambiental, com o seguinte título: "Métodos de controle da disseminação de espécies exóticas e alóctones 
a serem empregados durante o cultivo". Assim, as redações do artigo 19 e do Anexo III promoveram o entendimento de que o aquicultor é responsável pela manutenção dos espécimes no âmbito do cativeiro, devendo adotar barreiras que impeçam a disseminação das espécies que não apresentam ocorrência natural na UGR em questão (Brasil, 2009a).

Essa posição foi corroborada na Lei ${ }^{\circ} 11.959$ de 29 de junho de 2009, que dispõe sobre a política nacional de desenvolvimento sustentável da aquicultura e da pesca, conforme prevê o artigo abaixo:

Art. $22^{\circ}$ : Na criação de espécies exóticas, é responsabilidade do aquicultor assegurar a contenção dos espécimes no âmbito do cativeiro, impedindo seu acesso às águas de drenagem de bacia hidrográfica brasileira (Brasil, 2009b).

Mesmo com o aperfeiçoamento das diretrizes para cultivo de espécies exóticas, o estado do Pará permaneceu desalinhado com as normas federais e optando por uma legislação mais restritiva. Esta posição fica evidente na Instrução Normativa ${ }^{\circ} 04$ de 10 de maio de 2013 da Secretaria de Estado de Meio Ambiente e Sustentabilidade do Pará (SEMAS), a qual define os processos para licenciamento ambiental de empreendimentos aquícolas no território. A norma não esclarece acerca dos sistemas de produção e, especificamente sobre o assunto, estabelece somente que empreendimentos de pequeno porte com espécies exóticas não são passíveis de dispensa de licenciamento ambiental (Pará, 2013).

Desta forma, o cenário da regularização estadual para piscicultura com espécies exóticas não sofreu qualquer alteração em função da nova norma jurídica. No âmbito municipal, Paragominas regulamentou a criação de espécies exóticas em sistema fechado em seu território por meio da Lei $n^{\circ} 961$ de 17 de maio de 2018, elucidando as definições pendentes na legislação estadual (Paragominas, 2018).

Essa iniciativa e a sua perspectiva de propagação para outros municípios provavelmente motivaram o estado a editar a Resolução COEMA n 143 de 20 de dezembro de 2018, que dispõe sobre as diretrizes para o cultivo de espécies exóticas em empreendimentos aquícolas no Pará. Nesta resolução foi possível o entendimento de conceitos pendentes, conforme elucidado nos seguintes parágrafos:

Art. $2^{\circ}$ : Para efeitos desta norma, entende-se por: III - sistema aberto: é o sistema em que o corpo hídrico superficial é diretamente utilizado como local de cultivo;

IV - sistema parcialmente fechado: é o sistema em que a água é captada de uma fonte hídrica até uma infraestrutura de cultivo localizada em bases terrestres, havendo lançamento do efluente em corpo hídrico superficial;

V - sistema fechado: é o sistema em que a água é captada de uma fonte hídrica até a infraestrutura de cultivo localizada em bases terrestres, sem que haja lançamento do efluente em corpo hídrico superficial (Pará, 2018).

A resolução apresenta como exigência para regularização dos empreendimentos a adoção de sistema fechado de produção, bem como a aplicação de medidas que visem o controle da espécie no cativeiro:

Art. $3^{\circ}$ : O órgão ambiental competente autorizará o cultivo de espécies exóticas em sistemas fechados, observados, no mínimo, os seguintes critérios:

I - obtenção e produção de peixes com reversão sexual certificada, quando houver técnica disponível e economicamente viável para a espécie;

II - os viveiros e tanques contendo animais exóticos 
devem possuir proteção para evitar ação de aves predadoras; e

III - destinação adequada de resíduos e efluentes (Pará, 2018).

No caso dos empreendimentos que adotam sistema parcialmente fechado, a norma condiciona a regularização à aprovação prévia da tecnologia a ser empregada, comprovando sua eficácia na manutenção da espécie restritamente ao ambiente de cultivo:

Art. $4^{\circ}$ : O órgão ambiental estadual competente poderá autorizar o cultivo de espécies exóticas em empreendimentos que adotam sistemas parcialmente fechados para validação de propostas técnicas que visem assegurar a contenção dos organismos cultivados no local de confinamento e evitem propagação de espécies exóticas para o ambiente natural.

$\S 1^{\circ} \mathrm{A}$ aplicação das propostas técnicas referidos no caput deste artigo, poderá ser acompanhada por instituição pública de ensino e/ou pesquisa, com atuação reconhecida na área de aquicultura, pelo órgão ambiental estadual e pelas instituições estaduais de fomento e extensão.

$\S 2^{\circ}$ As propostas técnicas reconhecidas e validadas pela instituição pública de ensino e/ou pesquisa, pelo órgão ambiental estadual e pelas instituições estaduais de fomento e extensão serão submetidas à regulamentação através de Resolução do Conselho Estadual de Meio Ambiente para serem aplicadas em território estadual (Pará, 2018).

As iniciativas que empregam o sistema aberto de produção continuam impossibilitadas de regularização no estado do Pará, valendo-se do artigo 29 da Lei de $\mathrm{n}^{\circ} 6.713$ de 25 de janeiro de 2005 que considera a prática como atividade ilegal. As propostas técnicas para o licenciamento ambiental da tilapicultura deverão ser submetidas em acordo aos termos estabelecidos na Instrução Normativa $\mathrm{n}^{\mathrm{o}} 04$ de 10 de maio de 2013, observando o porte e o possível impacto do estabelecimento (Pará, 2005; 2013).

\section{Material e método}

\section{1. Área de estudo}

O estado do Pará está situado na região Norte do Brasil e apresenta uma extensão territorial de $1.245 .759 \mathrm{~km}^{2}$, a segunda maior do país. É dividido em 144 municípios, sua capital é Belém (01 $27^{\circ} 18^{\prime \prime}$ S; 48 30'09" W) e apresenta população estimada de 8.602.865 milhões de habitantes em 2019 (IBGE, 2019). O território possui uma privilegiada disponibilidade hídrica, sendo contemplado por três regiões hidrográficas de águas continentais: Amazônica, Tocantins-Araguaia e Atlântico Nordeste Ocidental (Figura 1) (Brasil, 2003c). Esta condição, somada ao clima adequado para a produção de espécies de peixes tropicais ao longo do ano inteiro, a diversidade de espécies com potencial zootécnico e mercadológico, bem como o elevado consumo per capita de pescado, conferem ao Pará uma distinta vocação para a piscicultura (Brabo et al., 2016b).

Apesar disso, no ano de 2017 a produção piscícola paraense foi de 13,5 mil toneladas e movimentou cerca de $\mathrm{R} \$ 110$ milhões, assumindo apenas a décima terceira colocação no ranking nacional. A piscicultura tem sido praticada predominantemente por mão de obra familiar com baixo nível de escolaridade, os quais a exercem como uma fonte de renda complementar e com mínimo grau de profissionalismo. Observa-se, ainda, que grande maioria não tem acesso a recursos financiáveis e operam sem regularização, que somados a deficiência de 
organização social da cadeia e de políticas públicas, refletem em nível de competitividade aquém do potencial do estado (De-carvalho et al., 2013; Oliveira et al., 2014; Zacardi et al., 2017; Viana et al., 2018; SIDRA, 2019).

De maneira geral, as pisciculturas paraenses são de pequeno porte com criação de peixes redondos em viveiros escavados, como o tambaqui Colossoma macropomum, a pirapitinga Piaractus brachypomus e os híbridos tambacu Colossoma ma- cropomum $\mathrm{x}$ Piaractus mesopotamicus e tambatinga Colossoma macropomum $\mathrm{x}$ Piaractus brachypomus. Além dessas, são produzidas em menor escala o piauçu Leporinus macrocephalus, o curimatã Prochilodus nigricans, o matrinxã Brycon amazonicus, o pintado amazônico Pseudoplatystoma reticulatum x Leiarius marmoratus, o pirarucu Arapaima gigas e a tilápia Oreochromis spp. (Brabo et al., 2016b; SIDRA, 2019; PEIXE-BR, 2020).

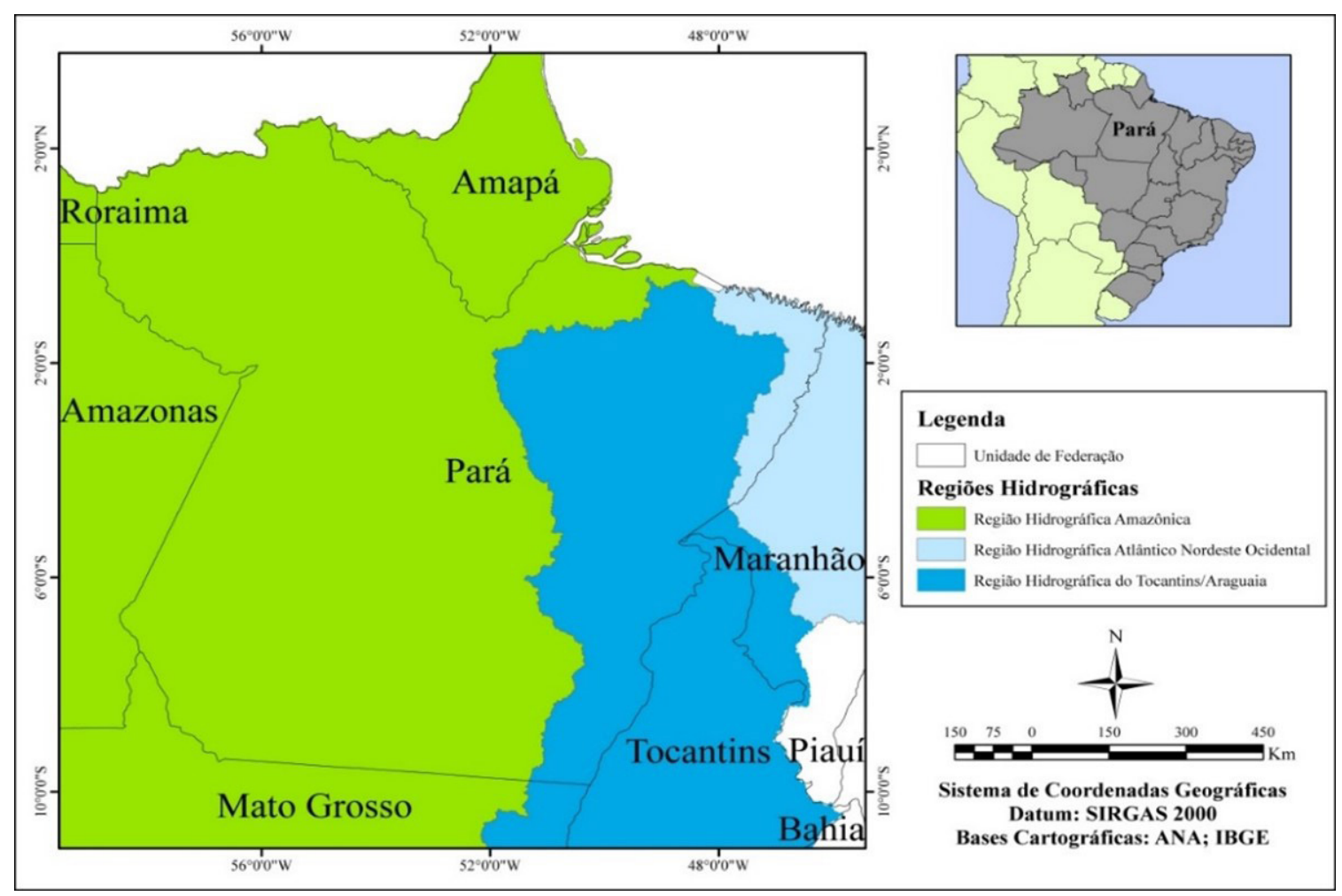

FIGURA 1 - Mapa territorial do estado do Pará inserido nas regiões hidrográficas Amazônica, Tocantins/Araguaia e Atlântico Nordeste Ocidental. FONTE: Elaborado pelos autores. 
No caso da tilápia, os municípios de Capitão Poço (0144'47' S 4703'57' W) e Paragominas (02 59'51" S 47²1'13" W) se destacam no cenário paraense. Em Capitão Poço, a tilápia é a espécie preferida da piscicultura e, nos últimos anos, tem acumulado o maior volume de produção da espécie no estado. No caso de Paragominas, embora não disponha de dados da produção para a espécie, este é o único município paraense que apresenta um ato normativo próprio para regularização da tilápia e, ainda, é o maior produtor de peixes do estado, dispondo de uma das cadeias de piscicultura mais bem estruturada (Brito et al., 2017; Paragominas, 2018; SIDRA, 2019).

\subsection{Coleta e análise de dados}

A coleta de dados para a caracterização do cenário atual da tilapicultura no estado do Pará teve início a partir de um levantamento de dados no Instituto Brasileiro de Geografia e Estatística (IBGE), com consulta ao Censo Agropecuário de 2017 e à Produção da Pecuária Municipal (PPM) dos anos de 2014 a 2018 por meio do Sistema IBGE de Recuperação Automática (SIDRA), visando obter o número de empreendimentos que utilizavam a espécie, a produção e seu valor monetário correspondente. Este órgão é o responsável pela estatística oficial da aquicultura brasileira desde 2013 e a disponibiliza por município, bem como georreferencia e caracteriza os estabelecimentos rurais a cada dez anos por meio do Censo Agropecuário.

Posteriormente, efetuou-se uma revisão da literatura disponível acerca da criação de tilápia no estado do Pará e consulta a piscicultores, comerciantes e especialistas do setor com atuação nas áreas de pesquisa e extensão, visando identificar as modalidades de produção adotadas pelos piscicultores, suas características e, principalmente, sua localização, dada a dificuldade de acesso devido a predominância de iniciativas em condição irregular de operação. Essas informações balizaram visitas a iniciativas comerciais em dezembro de 2019, para observações de campo e entrevistas semiestruturadas com os proprietários que abordaram aspectos tecnológicos e econômicos, como: instalações zootécnicas, produção, produtividade, manejo, custo de produção, preço de primeira comercialização e mercado consumidor.

A seleção dos empreendimentos analisados ocorreu de forma a viabilizar a exposição em caráter fundamentalmente qualitativo e descritivo das particularidades da atividade no estado do Pará em relação ao restante do país e a contemplar todas as modalidades praticadas comercialmente: tanques-rede, viveiros escavados e tanques suspensos em sistema de bioflocos. Para isso, foram visitadas três iniciativas que podem ser consideradas emblemáticas, uma no município de Capitão Poço, Nordeste paraense, e duas no município de Paragominas, Sudeste paraense.

A piscicultura selecionada em Capitão Poço utiliza a tilápia desde a década de 1980 e apresenta uma produção anual de aproximadamente 30 toneladas da espécie, exclusivamente em tanques-rede, o que provavelmente lhe garante o primeiro lugar no ranking estadual. Em Paragominas, uma das iniciativas escolhidas é a única com produção de alevinos revertidos sexualmente no território e a pioneira no uso de tanques suspensos com sistema de bioflocos, enquanto a outra faz engorda em viveiros escavados para comercialização e a utiliza como peixe forrageiro vivo para alimentação de 
pirarucu, o que representa a realidade da maioria dos tilapicultores paraense (Brabo et al., 2020).

Dispondo dos dados primários e secundários, inicialmente, foi realizado o ordenamento do número de empreendimentos, produção e valor monetário de cada município por região hidrográfica, considerando a distribuição de acordo com os mapas da Agência Nacional de Águas (ANA), o que possibilitou caracterizar a prática da atividade no território paraense por UGR (ANA, 2019). Em seguida, as informações obtidas em campo acerca das modalidades de produção foram dispostas de forma descritiva e argumentadas com base na literatura disponível. Por fim, as modalidades foram confrontadas com as exigências da Resolução COEMA n ${ }^{\circ} 143$ de 20 de dezembro de 2018 e analisadas em caráter essencialmente qualitativo quanto a possibilidade de regularização (Malterud, 2015; Pará, 2018).

\section{Resultados e discussão}

\subsection{Cenário atual da tilapicultura no estado do Pará}

\subsubsection{Produção, valor monetário e número de empreendimentos}

O Censo Agropecuário do IBGE no ano de 2017 identificou um total de 3.089 estabelecimentos rurais com criação de tilápia em 124 municípios paraenses, com a região hidrográfica Tocantins-Araguaia apresentando a maior concentração de empreendimentos, seguida pela Amazônica e pela Atlântico Nordeste Ocidental, respectivamente (Tabela 1).

Do número de iniciativas identificadas de tilapicultura, 76,9\% dos estabelecimentos são enquadrados como empreendimento familiar rural, embasados na Lei n 11.326 de 24 de julho de 2006, que estabelece as diretrizes para a formulação da política nacional da agricultura familiar e de empreendimentos familiares rurais. No caso da aquicultura, além dos critérios gerais da propriedade e da operacionalização de suas atividades produtivas, o porte das iniciativas considerado é de até dois hectares no caso de reservatórios hídricos ou até $500 \mathrm{~m}^{3}$ de tanques-rede (Brasil, 2006).

Constatou-se que a produção de tilápia no estado do Pará variou de 233,3 a 384 toneladas entre 2014 e 2018, o que correspondeu entre 1,9 e 2,8\% do total da piscicultura paraense, respectivamente

TABELA 1 - Número de empreendimentos e de municípios praticando tilapicultura no estado do Pará por região hidrográfica no ano de 2017.

\begin{tabular}{lcccc}
\hline \multicolumn{1}{c}{ Região hidrográfica } & Número de empreendimentos & $\mathbf{\%}$ & Número de municípios & \% \\
\hline Amazônica & 671 & 21,7 & 27 & 21,8 \\
Tocantins-Araguaia & 2.044 & 66,2 & 70 & 27 \\
Atlântico Nordeste Ocidental & 374 & 12,1 & 21,8 \\
\hline Total & $\mathbf{3 . 0 8 9}$ & $\mathbf{1 0 0}$ & $\mathbf{1 2 4}$ & $\mathbf{1 0 0}$ \\
\hline
\end{tabular}

FONTE: Sistema IBGE de Recuperação Automática - SIDRA, 2019. 
(Figura 2). Ao considerar o dado mais recente, nota-se que o volume de 262,8 toneladas em 2018 foi incipiente em relação à produção nacional de tilápia, que foi de 311,5 mil toneladas, no entanto representou $63,5 \%$ do total da Região Norte, em que os sete estados somaram 413,6 toneladas (SIDRA, 2019).

No cenário da piscicultura paraense, a tilápia perde espaço para os peixes nativos, especialmente para o tambaqui, o qual assume $62,9 \%$ do total da produção estadual. Este cenário é uma realidade da região Norte como um todo, onde os peixes redondos são as espécies alvo da piscicultura enquanto que a tilápia tem pouco expressividade, possivelmente por apresentar atos normativos mais restritivos que no resto do Brasil. No restante do país a tilápia é a principal espécie da piscicultura, excetos no estado do Rio Grande do Sul em que é baseada em carpas e no Mato Grosso, que a tilápia divide espaço com o tambaqui (SIDRA, 2019; PEIXE-BR, 2020).

De acordo com os dados da Produção da Pecuária Municipal do IBGE, 46 municípios paraenses produziram tilápia em pelo menos um ano do período de 2014 a 2018. Neste contexto, os municípios da região hidrográfica Tocantins-Araguaia foram responsáveis pela maior parcela da produção estadual em 2018, seguida pelas regiões Atlântico Nordeste Ocidental e Amazônica.

Dos 24 municípios inseridos na região hidrográfica Tocantins-Araguaia com produção de tilápia, 15 apresentaram números decrescente no período. Água Azul do Norte, Garrafão do Norte e Capitão Poço assumiram protagonismo em termos de volume produzido, enquanto Garrafão do Norte, Abaetetuba e Xinguara destacaram-se em relação ao incremento da produção (Tabela 2).

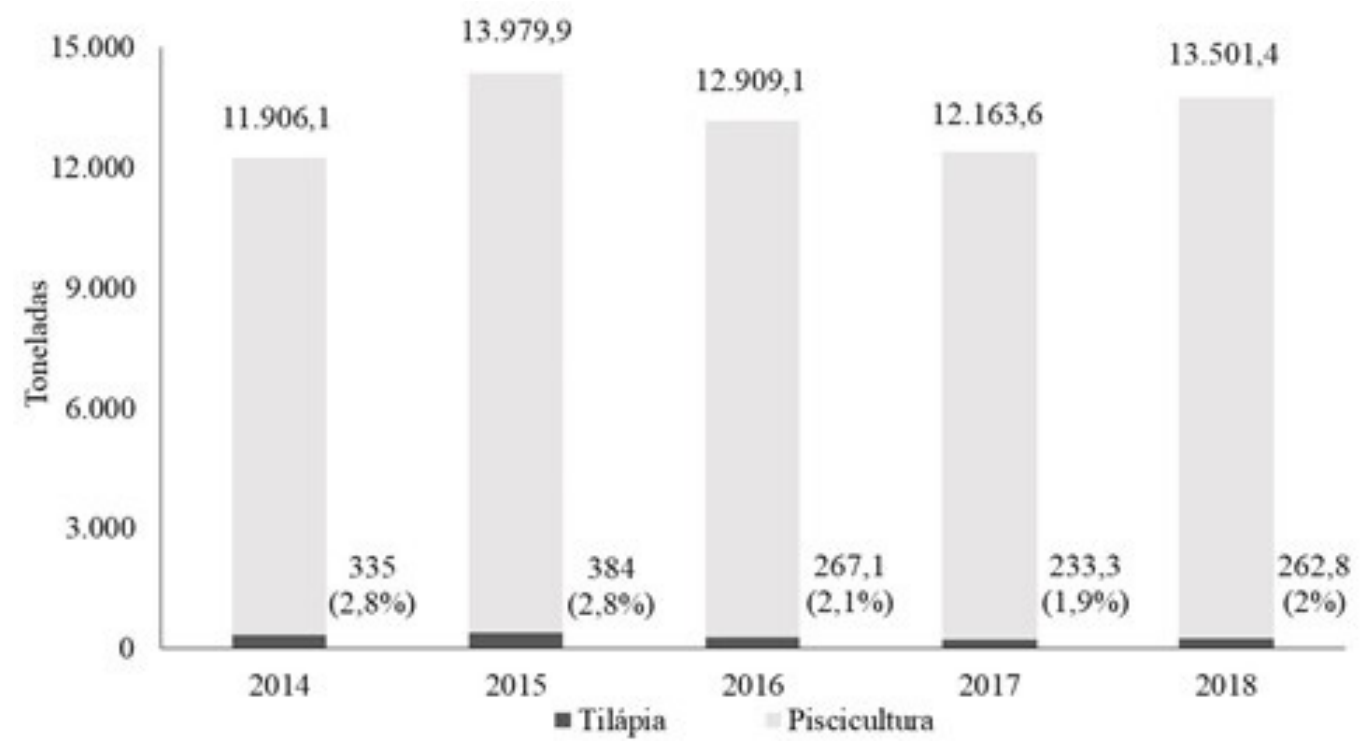

FIGURA 2 - Participação da produção de tilápia Oreochromis spp. em relação ao total da piscicultura no estado do Pará entre 2014 e 2018. FONTE: Sistema IBGE de Recuperação Automática - SIDRA, 2019. 
TABELA 2 - Produção de tilápia no período de 2014 a 2018 e seu valor monetário correspondente nos municípios paraenses pertencentes a região hidrográfica Tocantins-Araguaia.

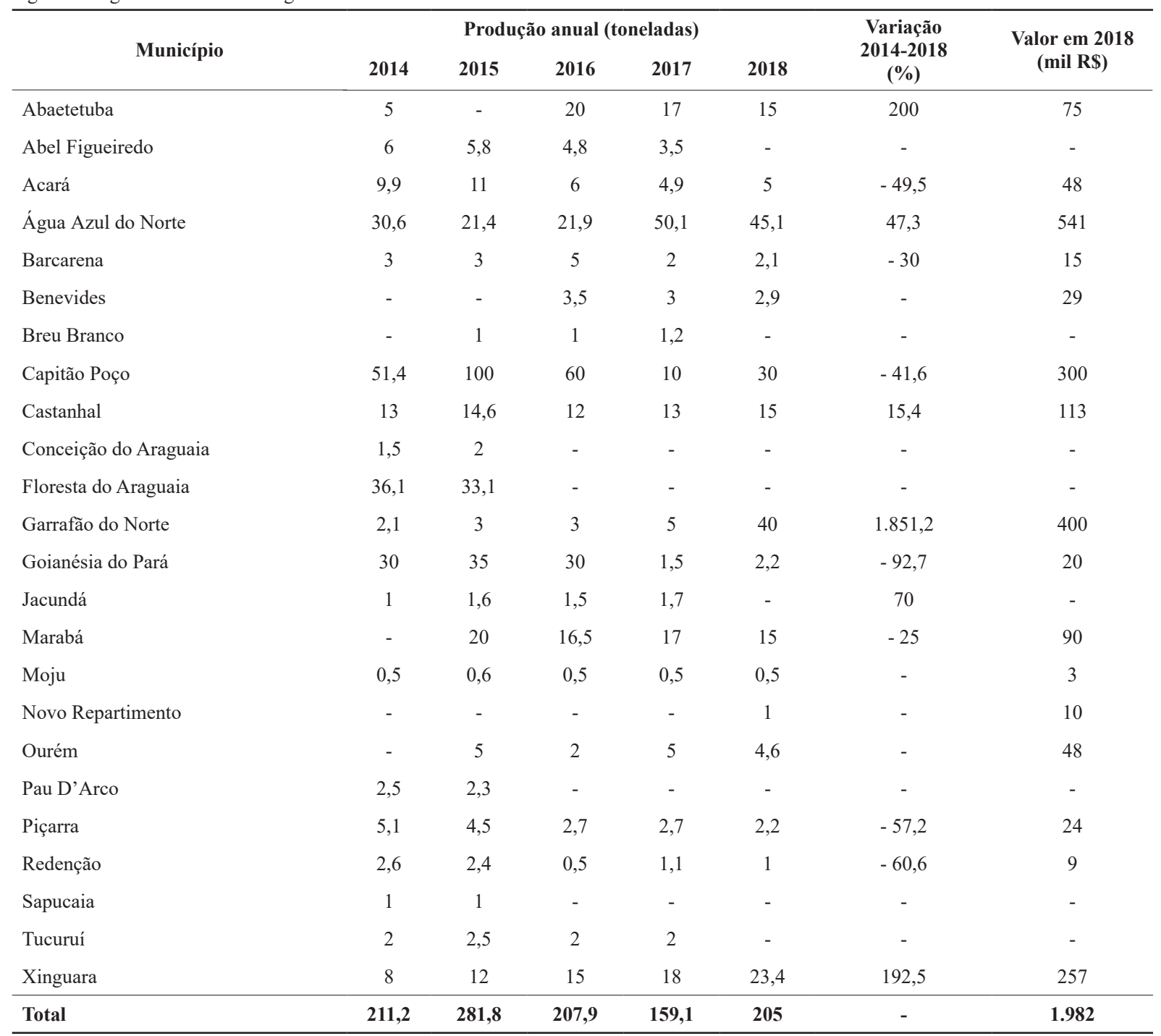

FONTE: Sistema IBGE de Recuperação Automática - SIDRA, 2019. 
Conforme constatado, o volume de produção e o número de empreendimentos de tilapicultura estão concentrados sobretudo na região Tocantins-Araguaia. Observa-se que esta tendência se aplica a piscicultura como um todo, uma vez que 47,9\% de todo peixe produzido no estado está presente na referida bacia hidrográfica, o que possivelmente representa a região com a cadeia produtiva mais desenvolvida no estado (SIDRA, 2019). Desse modo, a produção de tilápia no Tocantins-Araguaia pode ser um reflexo natural do desenvolvimento e diversificação da atividade na região ou, ainda, graças a rusticidade que a espécie dispõe, como forma de agregar na alimentação de peixes carnívoros e como espécie secundária na produção de redondos (Brabo et al., 2016b; Brabo et al., 2020).

Nos 13 municípios da região hidrográfica Atlântico Nordeste Ocidental com produção de tilápia, Peixe-boi, Capanema e Igarapé-Açu apresentaram os números mais significativos em 2018, com 10,5, 8,5 e 6 toneladas, respectivamente. Entre 2014 e 2018, apenas Igarapé Açu e São Francisco do Pará tiveram oferta do produto em todos os anos e exibiram variação positiva (Tabela 3 ).

Na região hidrográfica Amazônica, os municípios Brasil Novo, Uruará e Bannach apresentaram maiores produções de tilápia no ano de 2018, com 5,5, 5 e 2,4 toneladas, respectivamente (Tabela 4).

TABELA 3 - Produção de tilápia no período de 2014 a 2018 e seu valor monetário correspondente nos municípios paraenses pertencentes a região hidrográfica Atlântico Nordeste Ocidental.

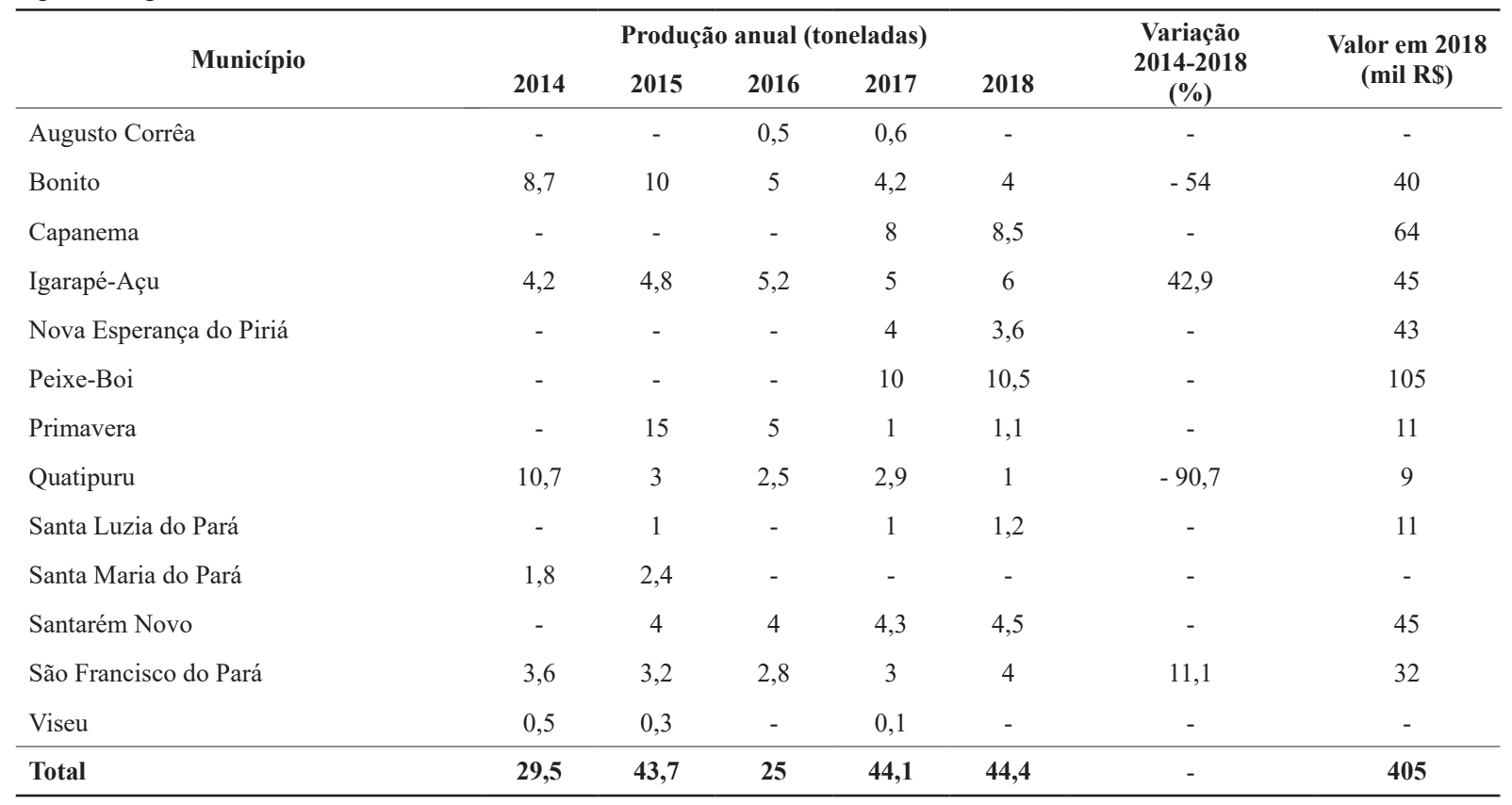

FONTE: Sistema IBGE de Recuperação Automática - SIDRA, 2019. 
TABELA 4 - Produção de tilápia no período de 2014 a 2018 e seu valor monetário correspondente nos municípios paraenses pertencentes a região hidrográfica Amazônica.

\begin{tabular}{|c|c|c|c|c|c|c|c|}
\hline \multirow{2}{*}{ Município } & \multicolumn{5}{|c|}{ Produção anual (toneladas) } & \multirow{2}{*}{$\begin{array}{c}\text { Variação } \\
2014-2018 \\
(\%)\end{array}$} & \multirow{2}{*}{$\begin{array}{l}\text { Valor em } 2018 \\
\quad(\text { mil R\$) }\end{array}$} \\
\hline & 2014 & 2015 & 2016 & 2017 & 2018 & & \\
\hline Belterra & 0,8 & - & - & - & - & - & - \\
\hline Brasil Novo & 62,8 & 34,5 & 17,3 & 18,5 & 5,5 & $-91,2$ & 55 \\
\hline Óbidos & 0,3 & - & - & - & 0,1 & $-83,6$ & - \\
\hline Oriximiná & 0,2 & 0,1 & 0,1 & - & - & - & - \\
\hline São Félix do Xingu & 1 & 0,9 & 0,6 & - & - & - & - \\
\hline Tucumã & 5,4 & 4 & 1,2 & - & 0,5 & $-90,7$ & 4 \\
\hline
\end{tabular}

FONTE: Sistema IBGE de Recuperação Automática - SIDRA, 2019.

Constata-se, ainda, que a produção da espécie demonstrou um declínio ao longo de todo o período, o que pode ser em consequência do mercado de pescado na região, uma vez que a piscicultura na região sofreu uma redução média de $4 \%$ ao ano, inclusive das principais espécies cultivadas como o tambaqui, tambacu e pirarucu. A região contribui com apenas $16,5 \%$ da produção estadual de peixes e tem sido vista como atividade secundária aos produtores, dispondo de viveiros com baixa produtividade e deficiência de acompanhamento técnico (Oliveira et al., 2014; SIDRA, 2019).

O preço médio de primeira comercialização do produto vivo ou fresco passou de $\mathrm{R} \$ 7,76$ para $\mathrm{R} \$ 9,55$ por quilograma no ano de 2014 a 2018, representando um crescimento de $23 \%$ no período (Tabela 5). Comparativamente, no estado do Paraná, o maior produtor de tilápia do Brasil, a espécie responde por $95 \%$ de toda a produção estadual e que equivale 115,2 mil toneladas, movimentando

TABELA 5 - Valor da produção e preço de comercialização da tilápia no estado do Pará entre anos de 2014 e 2018.

\begin{tabular}{cccc}
\hline Ano & Produção (toneladas) & Valor total (milhões.R\$) & Comercialização (R\$.kg-1) $^{-1}$ \\
2014 & 335,0 & 2,60 & 7,76 \\
2015 & 384,0 & 3,30 & 8,59 \\
2016 & 267,1 & 2,22 & 8,31 \\
2017 & 233,3 & 2,11 & 9,03 \\
2018 & 262,8 & 2,51 & 9,55 \\
\hline
\end{tabular}

FONTE: Sistema IBGE de Recuperação Automática - SIDRA, 2019. 
a economia com R $\$ 586$ milhões por um preço de primeira comercialização de $\mathrm{R} \$ 5,08 . \mathrm{kg}^{-1}$ (SIDRA, 2019). Segundo Ahmed et al. (2012), o preço de comercialização da tilápia possui uma relação inversa com a oferta do produto, uma vez que a baixa disponibilidade do produto no mercado aliado a insuficiência de suprimentos da cadeia produtiva tende a refletir no preço de venda da espécie.

\subsubsection{Modalidades de produção praticadas comercialmente}

\subsubsection{Criação de tilápia em viveiros escavados}

Historicamente, a criação de tilápia em viveiros escavados teve início na década de 1970 nos municípios de Santa Isabel do Pará e Santo Antônio do Tauá, sendo considerada a primeira modalidade de piscicultura ocorrida no estado do Pará. No início, a adoção desta modalidade de produção em escala comercial foi comprometida pela reprodução precoce e excessiva da espécie, contudo, quando as iniciativas de fornecimento de formas jovens revertidas sexualmente começaram a se popularizar, inclusive com suporte técnico do estado, houve a publicação da Lei n ${ }^{\circ} 6.713$ de 25 de janeiro de 2005, inviabilizando a regularização dos empreendimentos.

Ainda assim, atualmente, inúmeros açudes encontram-se povoados com tilápia no território paraense, o que pode ser caracterizado como piscicultura extensiva. Alguns deles sem a possibilidade de drenagem total e com sangradouros que viabilizam a continuidade dos cursos d'água que sofreram barramentos. No caso dos viveiros escavados, os dois fatores principais que motivam a manutenção da espécie nas propriedades são: a utilização como peixe forrageiro vivo para carnívoros e o mercado consumidor atraente, inclusive para tilápias de pequeno porte.

Em uma das propriedades avaliadas no município de Paragominas, a produção de tilápia ocorria em viveiro escavado em sistema de policultivo com a tambatinga há mais de cinco anos. No geral, a piscicultura contava com 19 estruturas de 50 metros de largura por 100 metros de comprimento cada, totalizando 9,5 hectares de lâmina d'água, os quais eram abastecidos por bombeamento a partir de um reservatório de aproximadamente quatro hectares. Desse montante de viveiros escavados, utilizava-se apenas um para policultivo.

A densidade de estocagem para a tambatinga ocorria com um (1) peixe por $\mathrm{m}^{2}$ e para a tilápia, por não dispor de um manejo efetivo, não havia estimativa da quantidade de indivíduos presente no cultivo, haja visto que na despesca não se realizava a drenagem total dos viveiros, apenas o arrasto para a retirada dos peixes de acordo com a demanda dos compradores. Desta forma, a estimativa de produção anual da tambatinga correspondia de 2,4 a 3,5 toneladas e da tilápia em torno de 0,4 a 0,5 tonelada.

As formas jovens da espécie foram provenientes do estado do Maranhão e utilizadas no povoamento do açude responsável pelo abastecimento deste viveiro utilizado para policultivo e de mais um segundo açude a jusante de dois hectares de lâmina d'água com criação extensiva de pirarucu. No caso do viveiro, por não ser realizada a drenagem total do ambiente, não ocorria preparação entre os ciclos de produção, como o vazio sanitário e calagem, o que impossibilitava o acompanhamento e controle da densidade de tilápia. 
O fornecimento de ração ocorria duas vezes ao dia até a saciedade aparente dos peixes e a conversão alimentar acumulada para a tambatinga se apresentava em 2:1 para um ciclo de produção anual. No caso da tilápia, em virtude da ausência de controle da prolificidade e a reprodução ocorrer de forma desordenada sem reversão sexual, não era possível acompanhar o desempenho zootécnico e a conversão alimentar da espécie. O volume de água drenado na despesca tinha como destino o açude de dois hectares, que esporadicamente também recebia tilápias de até $0,1 \mathrm{~kg}$ de forma in natura ou em pedaços para alimentação dos pirarucus, as quais eram capturadas nas despescas parciais para comercialização do peixe redondo.

$\mathrm{O}$ peso de abate da tambatinga ocorria em aproximadamente $1,5 \mathrm{~kg}$ e da tilápia a partir de $0,25 \mathrm{~kg}$, para um preço de $\mathrm{R} \$ 6,00$ por quilograma em ambos os casos. A comercialização da tilápia se dava com o produto inteiro fresco à varejistas do próprio município e de cidades vizinhas que adquiriam o pescado no interior da propriedade. $\mathrm{O}$ produtor relatou como uma das principais dificuldades para a tilapicultura no estado a ausência de insumos como alevinos de tilápia revertidos sexualmente e a indisponibilidade de ração especifica para a espécie no estado.

Segundo a literatura, a tilapicultura paraense ocorre principalmente em viveiros escavados e a prática do policultivo é o principal meio de produção adotado comercialmente, visto como uma possibilidade de aumento no número de despescas por ano. A espécie está presente de forma secundária e sua alimentação ocorre por meio do aproveitamento das sobras de ração e dos resíduos gerados pela espécie principal (Silva et al., 2010; De-Carvalho et al., 2013; O’ de Almeida-Junior \& Souza, 2013;
Zacardi et al., 2017; Brabo et al., 2020). Contudo, o policultivo visitado demonstrou que a prática ocorre sem o controle zootécnico e com superpopulação de indivíduos abaixo do tamanho comercial, o que dificulta o planejamento da atividade e das estratégias de produção.

O peso de abate e a forma de comercialização empregado nesta modalidade de produção estão em conforme com o apresentado na literatura, as quais ocorrem diretamente ao consumidor final ou a peixarias locais em peso entre 0,2 a $1,5 \mathrm{~kg}$ com o produto inteiro fresco (Brabo et al., 2016c; Brabo et al., 2020). O uso da tilápia como peixe forrageiro na alimentação de peixes carnívoros, como o pirarucu, é um meio de diminuir a necessidade de alimento artificial e a espécie se destaca pela não necessidade de reposição constante de reprodutores, haja visto que, ao atingir determinado porte, a predação se torna menos eficiente e a tilápia passa ser matriz reprodutora (Zacardi et al., 2017; SIDRA, 2019; Brabo et al., 2020).

\subsubsection{Criação de tilápia em tanques-rede}

O cultivo de tilápia em tanques-rede ocorre no estado desde a década de 1990, em sua maioria com estruturas de pequeno volume, geralmente de 4 a $6 \mathrm{~m}^{3}$, instaladas em açudes originados a partir de pequenos barramentos. Contudo, houveram diversas iniciativas implantadas no leito de rios, como no Guamá e no Inhangapi, inclusive nos anos 2000. O uso de estruturas improvisadas, com telas de contenção pouco resistentes e suportes de madeira era comum, assim como escapes dos espécimes em confinamento. Na época, a produção em tanques-rede era uma novidade entre os piscicultores paraenses 
e a tilápia era a única espécie recomendada para empreendimentos comerciais.

O empreendimento analisado no município de Capitão Poço produzia tilápia em 50 tanques-rede de $4 \mathrm{~m}^{3}$ de volume útil instalados em um reservatório hidráulico de dois hectares de lâmina d'água e cerca de quatro metros de profundidade, localizado integralmente na área da propriedade rural. A formação deste açude ocorreu a partir da construção de uma barragem de terra com 100 metros de comprimento e cinco metros de altura em uma microbacia hidrográfica dotada de três nascentes devidamente preservadas.

O excesso de água no reservatório era drenado por dois sangradouros, um (1) em cada extremidade da barragem, que se comunicavam com o canal de drenagem dos tanques e viveiros escavados localizados a jusante. Na época da construção, a principal finalidade do açude era abastecer por gravidade as demais estruturas hidráulicas utilizadas para piscicultura, o que demandava a captação nas proximidades de um dos sangradouros por meio de tubulações de policloreto de polivinila (PVC) para um canal de abastecimento que alimentava os tanques e viveiros escavados individualmente.

Os tanques-rede, fabricados na propriedade, estavam dispostos em quatro baterias, com a primeira a aproximadamente 10 metros da barragem e as demais separadas entre si pela mesma distância. Quanto ao espaçamento entre as estruturas, o padrão era de quatro metros e a distância entre a sua parte inferior e o substrato de cerca de dois metros. A tela de contenção dos peixes dos tanques-rede constituía-se de arame galvanizado revestido de PVC com suportes em alumínio e flutuadores em bombonas plásticas de 20 litros ou tubos de PVC de 100 milímetros.
A produção de tilápia correspondia a aproximadamente 30 toneladas.ano ${ }^{-1} \mathrm{com}$ produtividade estimada entre 130 e $150 \mathrm{~kg} \cdot \mathrm{m}^{-3} \cdot \mathrm{ano}^{-1}$. As formas jovens utilizadas não passavam pelo processo de reversão sexual e advinham de reproduções naturais que ocorriam sem os cuidados com proporções de macho e fêmea, as quais se realizavam em viveiros escavados. Constantemente separava-se as tilápias umas das outras a fim de uniformizá-las por tamanho e, quando observado indivíduos com peso entre 0,05 e $0,1 \mathrm{~kg}$, ocorria o envio aos tanques-rede. Neste cenário, comumente se adquiria formas jovens em outros estados para a formação de novas matrizes objetivando a busca por variabilidade genética aos reprodutores, como Paraná, Alagoas, Maranhão e Tocantins.

A densidade de estocagem adotada na engorda foi de 125 peixes.m-3 ${ }^{-3}$, a duração do ciclo de produção de 120 dias, a conversão alimentar aparente de $2: 1$ e o peso de abate era de 0,4 a $0,5 \mathrm{~kg}$. Segundo o produtor, Técnico Agropecuário com experiência de mais de 30 anos na área da piscicultura, o custo de produção estava em torno de $\mathrm{R} \$ 6,00 . \mathrm{kg}^{-1}$ para o ano de 2019, com a variação ocorrendo principalmente em função do preço das rações e do seu frete.

O preço recebido pelo piscicultor na primeira comercialização foi de $\mathrm{R} \$ 10,00$ por quilograma do peixe vivo em 2019, o qual ocorria a varejistas de Capitão Poço e municípios vizinhos que adquiriam o produto na propriedade por três vezes na semana. Apesar da significativa margem de lucro, o piscicultor relatou a concorrência com a tilápia oriunda de outros estados como um dos principais fatores limitantes para uma maior prosperidade do negócio, visto que a prática deste preço só era possível devido a estratégias comerciais estabelecidas em parceria com os varejistas. 
A tilapicultura em tanques-rede é a modalidade de produção que ocorre em menor expressão no estado, contudo, apresenta superioridade quanto aos índices de desempenho zootécnico, haja visto que nestas estruturas a produtividade varia entre 150 a 300 kg.m ${ }^{-3}$.ano ${ }^{-1}$ (Brabo, 2014; Souza \& Leite, 2016; Brabo et al., 2020). Além do mais, esta modalidade de produção apresenta investimento inicial em estruturas e variação dos parâmetros físico-químicos da água menor que dos viveiros escavados (Furlaneto et al., 2006).

A regularização ambiental do cultivo em tanques-rede pode ser por vias federais ou estaduais. No primeiro caso, quando se utiliza águas de responsabilidade da União, as diretrizes são definidas pelo Decreto $n^{\circ} 4.895$ de 25 de novembro de 2003 e os procedimentos de habilitação dos contratos de cessão do uso da água são estabelecidos na Instrução Normativa $\mathrm{n}^{\mathrm{o}} 19$ de 13 de agosto de 2020 (Brasil, $2003 b$; 2020). Na esfera estadual, as diretrizes variam de acordo com o estado, como no caso do Paraná e Tocantins, por exemplo, estes consideram as regiões hidrográficas sob sua jurisdição para emissão de licença ambiental em cultivos de tanque rede (Tocantins, 2018; Paraná, 2019).

\subsubsection{Criação de tilápia em sistema de bioflocos}

A tilapicultura em sistemas de bioflocos é considerada a modalidade de produção mais recente no estado do Pará, e desde 2018, o único empreendimento regularizado no território está localizado no município de Paragominas. Neste empreendimento, além da engorda de tilápia em sistema de bioflocos, ocorre a larvicultura de tilápia revertida sexual- mente, bem como o cultivo de peixes redondos em viveiros escavados que somados representam um total de 50 hectares de lâmina d'água.

A larvicultura ocorria a partir da reprodução natural em uma hapa instalada em um tanque suspenso de $60 \mathrm{~m}^{3}$ com 100 fêmeas de tilápia do Nilo de aproximadamente $0,5 \mathrm{~kg}$ e 20 machos de tilápia Saint Peter Oreochromis spp. com cerca de $1,5 \mathrm{~kg}$. A renovação do plantel reprodutor se dava com aquisição de formas jovens advindas de outros estados, em que, após engorda-los na fazenda, ocorria a substituição dos reprodutores quando se observava baixa fecundidade das matrizes ou quando apresentava características físicas indesejáveis para reprodução.

A coleta de ovos na boca das fêmeas realizava-se uma vez por semana com uma estimativa de obtenção de 100 a 1.000 ovos por fêmea, os quais eram levados a oito incubadoras de 5,5 litros instaladas em uma edificação de madeira de 10 metros de comprimento por 30 metros de largura. Posteriormente, as larvas eclodidas mantinham-se em basquetas até o término do consumo do saco vitelínico, quando eram levadas a tanques suspensos de $2 \mathrm{~m}^{3}$ de volume útil para o processo de reversão sexual, que tinha eficiência estimada em $98 \%$ de masculinização.

Após 30 dias de reversão sexual, os alevinos de aproximadamente um (1) grama encaminhavam-se a seis tanques em geomembrana de polietileno de alta densidade (PEAD) de 1.000 micras com $60 \mathrm{~m}^{3}$ cada e sob aeração contínua, onde passavam cerca de 120 dias para atingir entre 0,4 e $0,5 \mathrm{~kg}$. A manutenção do sistema de bioflocos ocorria com açúcar comercial na relação 20:1 de carbono e nitrogênio e por um banco de bactérias, que combinava probiótico, farelo de arroz, bicarbonato de sódio e húmus de 
minhoca. A produtividade estimada correspondia a $15 \mathrm{~kg} \cdot \mathrm{m}^{-3}$ para uma conversão alimentar aparente de até 1,5:1, em que a comercialização ocorria a varejistas locais ao preço de $\mathrm{R} \$ 7,00 . \mathrm{kg}^{-1}$ com o pescado fresco sem qualquer beneficiamento, revelando um montante de 1.500 a $2.000 \mathrm{~kg}$ de tilápia por mês com o produto em peso acima de $0,4 \mathrm{~kg}$.

Importante ressaltar que as estruturas eram cobertas com rede anti-pássaro e a destinação dos efluentes nas renovações parciais ocorriam no entorno das estruturas, onde não havia perspectiva de alcançar cursos d'água superficiais. Inicialmente, o produtor relatou sobre a ausência de comercialização de formas jovens revertidas sexualmente no estado e da dificuldade em adquirir os alevinos, pois as empresas enviam os animais apenas em volume que compensa a distância entre as cidades, o que motiva a realização da alevinagem na propriedade. Além disso, foi destacado sobre a entrada de peixes para comercialização advindos de estados vizinhos, especialmente do Maranhão, com o preço mais atraente ao feirante que o repassado por produtores paraense.

A tecnologia de bioflocos tem como vantagem o maior controle dos efluentes do cultivo, biossegurança para entrada ou saída de patógenos e possibilidade de produtividade de até $40 \mathrm{~kg} . \mathrm{m}^{-3}$ (Avnimelech, 2012). Contudo, os custos de produção, investimento de implantação e exigência de profissional qualificado tornam um risco maior ao empreendedor quando comparado a sistemas convencionais (Rego et al., 2017).

A propriedade visitada dispõe de técnicas que diferem da realidade do estado, onde a grande maioria dos empreendimentos produzem suas formas jovens em meio a baixa qualidade genética dos reprodutores e sem passar pelo processo de reversão sexual, uma vez que não há comercialização de alevinos de tilápia revertido no estado (Brabo, 2014; Brabo et al., 2014; Brabo et al., 2016a; Brabo et al., 2020). O controle genético dos reprodutores tende a aumentar a taxa de crescimento e o rendimento de filé das proles, bem como a masculinização das formas jovens é essencial para controlar a prolificidade indesejada e manter o lote em crescimento mais uniforme, o que possibilita um incremento na produtividade do cultivo (Porto et al., 2015; Hasan et al., 2016).

\subsubsection{Sintese dos aspectos tecnológicos e econômicos das modalidades de produção praticadas comercialmente no estado do Pará}

As informações coletadas possibilitaram estabelecer os aspectos gerais das modalidades de produção de tilápia adotadas pelos piscicultores paraenses em empreendimentos comerciais (Tabela 6). Entre as particularidades observadas nas modalidades adotadas para a produção comercial da tilápia, está o cultivo bifásico para os tanques-rede, o baixo profissionalismo da produção em viveiros escavados e a unicidade do processo de reversão sexual em bioflocos.

No caso da produção em viveiro escavado, a falta de lotes masculinizados obriga a comercialização em pesos cada vez menores, enquanto que nos tanques-rede, a alta produtividade somente é permitida pelo fato de a espécie não realizar reprodução nestas estruturas, contudo, para isso, há a necessidade de uma fase em viveiro para que a espécie cresça a um tamanho suficientemente maior que a malha do tanque-rede. 
TABELA 6 - Síntese dos aspectos tecnológicos, econômicos e distribuição das modalidades de produção de tilápia Oreochromis spp. no estado do Pará.

\begin{tabular}{|c|c|c|c|}
\hline \multirow[b]{2}{*}{ Aspectos } & \multicolumn{3}{|c|}{ Modalidades de produção de tilápia } \\
\hline & Tanques-rede & Viveiros escavados & $\begin{array}{c}\text { Tanques suspensos em sistema de } \\
\text { bioflocos }\end{array}$ \\
\hline Peso inicial (kg) & 0,05 a 0,1 & 0,001 & 0,001 \\
\hline Reversão sexual & Não & Não & Sim \\
\hline Ciclo de produção (meses) & 4 & Indeterminado & 4 \\
\hline Alimentação & Ração extrusada & $\begin{array}{l}\text { Ração extrusada e alimentos } \\
\text { alternativos }\end{array}$ & Ração extrusada \\
\hline Peso de abate $(\mathrm{kg})$ & $>0,4$ & $>0,2$ & $>0,4$ \\
\hline Conversão alimentar aparente & $2: 1$ & Indeterminada & $1,5: 1$ \\
\hline Diversidade de espécies & Monocultivo & Monocultivo ou policultivo & Monocultivo \\
\hline \multicolumn{4}{|l|}{ 2. Econômicos } \\
\hline Investimento $^{1}$ & Baixo & Médio & Alto \\
\hline Custo de produção $^{1}$ & Médio & Baixo & Alto \\
\hline $\operatorname{Risco}^{1}$ & Médio & Baixo & Alto \\
\hline Produto & Vivo ou inteiro fresco & Vivo ou inteiro fresco & Vivo ou inteiro fresco \\
\hline Mercado & Local & Local & Local \\
\hline \multicolumn{4}{|l|}{ 3. Distribuição } \\
\hline
\end{tabular}

Legenda: (1) A comparação dos fatores econômicos entre as modalidades de produção baseou-se em constatações apresentadas por Furlaneto et al. (2006), Rego et al. (2017) e Trombeta et al. (2017) somado a intensidade demandada aos seguintes itens: investimento por capacidade de produção (R\$.kg-1.m-3); complexidade das estruturas e benfeitorias; mão de obra qualificada e monitoramento do sistema; (2) Número de empreendimentos: Baixo porque a Lei estadual n ${ }^{\circ} 6.713$ inibiu a expansão e Alto porque requer o mínimo grau de profissionalização no manejo e o mercado consumidor absorve a um peso de abate que viabiliza a manutenção da espécie no estado; (3) Único empreendimento regularizado no território paraense.

A realidade da tilapicultura paraense assemelha-se a encontrada na região costeira de Gana, onde a produção da espécie demanda de profissionalismo e de insumos básicos, tendo sido praticada como atividade secundária com o emprego de mão de obra familiar (Mireku et al., 2018). Em Bangladesh, assim como no Pará, a comercialização da espécie ocorre de maneira tradicional e pouco competitiva, sendo distribuída diretamente ao mercado local e com o pescado fresco e sem processamento (Ah- 
med et al., 2012). Por outro lado, a tilapicultura do Paraná dispõe de uma importante rede de relacionamento e de cooperação entre atores da cadeia de produção, bem como um conjunto de suprimento e profissionalismo que fortalecem a tilápia como a principal espécie da piscicultura no estado (Feiden et al., 2018; Barroso et al., 2019).

\subsection{Perspectiva de regularização dos empreendimentos frente às diretrizes da Resolução COEMA $n^{\circ} 143$ de 20 de dezembro de 2018}

A partir do cenário atual da tilapicultura no estado do Pará e das exigências previstas na Resolução COEMAn ${ }^{\circ} 143$ de 2018 para regularização dos empreendimentos é possível atestar que apenas os tanques suspensos em sistema de bioflocos possuem viabilidade técnica para seu atendimento imediato (Tabela 7). Contudo, o cumprimento das exigências não se restringe exclusivamente a aplicação de tecnologia em sistemas fechado, pois requer, ainda, a necessidade de implantação de proteção antipássaro e a aquisição de alevinos com reversão sexual certificada.

A Resolução COEMA n ${ }^{\circ} 143$ de 20 de dezembro de 2018 quando observada pelo ponto de vista jurídico é considerada um marco positivo para a tilapicultura paraense, haja visto que desde 2005 não havia clareza sobre os aspectos do licenciamento ambiental para espécies exóticas e a atividade seguia sem perspectiva de desenvolvimento (Pará, 2005; 2018). Contudo, do ponto de vista comercial, as condições impostas na resolução vão na contramão da realidade das iniciativas em operação no estado, o que tende a mantê-las na obscuridade da lei e sem possibilidade de crescimento de suas atividades.

TABELA 7 - Perspectiva de regularização das modalidades de produção de tilápia no território paraense frente às diretrizes da Resolução COEMA n 143 de 20 de dezembro de 2018.

\begin{tabular}{|c|c|c|c|}
\hline Modalidade de produção & $\begin{array}{c}\text { Sistema de } \\
\text { produção }\end{array}$ & Situação quanto à legislação & Dificuldades \\
\hline & & Atividade ilegal & \\
\hline Tanques-rede & Aberto & $\begin{array}{l}\text { Art. } 29 \text { da Lei estadual nº } 6.713 \\
\text { de } 2005\end{array}$ & - \\
\hline $\begin{array}{l}\text { Viveiros escavados com } \\
\text { drenagem em curso d'água } \\
\text { superficial }\end{array}$ & $\begin{array}{l}\text { Parcialmente } \\
\text { fechado }\end{array}$ & Sem diretrizes definidas & - \\
\hline \multirow{2}{*}{$\begin{array}{l}\text { Viveiros escavados sem } \\
\text { drenagem em curso d'água } \\
\text { superficial }\end{array}$} & \multirow[b]{2}{*}{ Fechado } & Passível de regularização & Diverge da realidade do Estado; \\
\hline & & $\begin{array}{l}\text { Art. } 3^{\circ} \text { da Resolução COEMA n } \\
143 \text { de } 2018\end{array}$ & $\begin{array}{l}\text { Custo na instalação e manutenção de rede } \\
\text { anti-pássaro; e obtenção de alevinos com } \\
\text { reversão sexual certificada }\end{array}$ \\
\hline $\begin{array}{l}\text { Tanques suspensos em sistema } \\
\text { de bioflocos }\end{array}$ & Fechado & $\begin{array}{l}\text { Passível de regularização } \\
\text { Art. } 3^{\circ} \text { da Resolução COEMA n } \\
143 \text { de } 2018\end{array}$ & $\begin{array}{l}\text { Requer a obtenção de alevinos com rever- } \\
\text { são sexual certificada }\end{array}$ \\
\hline
\end{tabular}


A complexidade ou incerteza regulatória tende a desencorajar os piscicultores de expandir suas operações para aproveitar oportunidades de mercado e dificultar suas atividades comerciais, de modo que, sem o devido licenciamento ambiental na atividade, é difícil um produtor almejar a participação em políticas de fomento ou garantir empréstimos de instituições financeiras. Além do mais, a demanda tecnológica poderá ocasionar a exclusão social de pequenos agricultores, sobretudo aqueles com menor capacidade financeira, os quais apresentam maior dificuldade em aplicar tecnologias de custos elevados e sofisticadas (Barroso et al., 2019).

Os estudos demonstram que a aquicultura em sistema fechado de produção tende a apresentar um custo de produção e investimento superior aos de sistemas convencionais, uma vez que demanda de um maior nível tecnológico e mão de obra técnica, ocasionando elevada sensibilidade e risco de investimento para essa atividade (Ngoc et al., 2016; Rego et al., 2017; Santos-Filho et al., 2017). Desse modo, o cumprimento das exigências estabelecidas nesta resolução tende a diminuir a competitividade com o preço do pescado que entra no território paraense, bem como limitará o produtor a comercialização, principalmente, ao mercado local haja visto o menor poder de negociação.

Os relatos indicam que a entrada deste pescado é proveniente de estados vizinhos que permitem a tilapicultura em sistemas que demandam de menor investimento e complexidade, como o tanque-rede e viveiro escavado, tornando o preço de comercialização mais atraente que os praticados no Pará. Além disso, outro ponto que merece reflexão, é o fato de que estes estados apresentam em seu território as mesmas regiões hidrográficas presente no estado paraense, demonstrando rigor e interpretação diferentes para a mesma realidade hidrográfica.

O estado do Mato Grosso, por exemplo, coberto principalmente pela região Amazônica, possibilita o licenciamento de tilápia em tanque-rede e a dispensa de licenciamento para o pequeno produtor em viveiros escavados (Mato Grosso, 2017; 2018). No Maranhão, presente na região Atlântico Nordeste Ocidental, pouco se encontra sobre regulamentação de exóticos na literatura, contudo, destaca-se a dispensa de licenciamento para produtores familiares em viveiro escavado e tanque-rede (Maranhão, 2010). Nestes estados o volume de produção é ligeiramente superior ao produzido no território paraense, o que permite a comercialização a um preço até $89 \%$ mais baixo que o praticado no Pará (SIDRA, 2019).

$\mathrm{O}$ estado do Tocantins merece uma atenção por estar na região Norte e ser banhado pela região hidrográfica Tocantins-Araguaia, a qual apresenta maior concentração de tilapicultura no Pará. A Resolução COEMA/TO n 88 de dezembro de 2018 viabiliza a criação da tilápia em tanque-rede e considera como justificativa a portaria do IBAMA $\mathrm{n}^{\mathrm{o}} 27$ de 2003, que inclui a tilápia nilótica como detectada na bacia do Araguaia/Tocantins. Esta norma é uma atualização da portaria do IBAMA $\mathrm{n}^{\circ} 145$ de 1998 e ambas mostram que a tilápia tem o status de detectada nas três regiões hidrográficas presente no estado do Pará (Brasil, 1998b; 2003a; Tocantins, 2018; SIDRA, 2019).

Observa-se que a publicação do novo marco regulatório paraense ocorreu quase que simultaneamente a resolução do estado tocantinense. Contudo, o que se observa são perspectivas distintas de desenvolvimento, enquanto que no Pará pouco mudou, o Tocantins vem construindo uma base 
para o crescimento da atividade, recebendo investimentos ao setor de alevinagem e melhoramento genético da espécie, fortalecendo discussões sobre a cadeia e destinando créditos exclusivos à atividade, elementos fundamentais para o estado do Tocantins figurar-se como um dos maiores produtores de tilápia do Brasil (Tocantins, 2019a; 2019b; 2020).

\section{Conclusões}

Atualmente, a produção de tilápia é incipiente no contexto da piscicultura paraense e a tecnologia empregada pela maioria dos empreendimentos é defasada em relação ao restante do país, assim como a cadeia é desestruturada e indispõe de insumos básicos para produção da espécie. Contudo, mesmo com as restrições legais e com baixo profissionalismo nas técnicas de cultivo, existem iniciativas de tilapicultura em todas as regiões hidrográficas de águas continentais do estado do Pará, e o mercado absorve um importante volume do produto produzido localmente e em outros estados.

A Resolução COEMAn ${ }^{\circ} 143$ de 20 de dezembro de 2018 tende a comprometer a competitividade dos empreendimentos de tilapicultura no território paraense, dado a elevada necessidade técnico-estrutural demandado pelos sistemas fechados. Além disso, a normativa tende a manter a maioria das iniciativas em operação na ilegalidade, visto que não há perspectivas de regularização para os empreendimentos em tanques-redes instalados em reservatórios particulares e não dispõe de alternativas para viveiros escavados em sistema parcialmente fechado.

As normas jurídicas federais que tratam do uso de espécies exóticas na aquicultura o fazem conside- rando as regiões hidrográficas como condicionante ao cultivo, enquanto o estado do Pará legisla sobre o assunto a partir do seu território como um todo. Esta postura torna ineficiente o rigor da legislação paraense, visto que estados na mesma região hidrográfica apresentam regulamentações diferenciadas, como é o caso do Tocantins na Tocantins-Araguaia, do Mato Grosso na Amazônica e do Maranhão na Atlântico Nordeste Ocidental.

O presente estudo reforça o papel imprescindível das instituições do governo do estado para o fortalecimento da tilapicultura e ressalta o rigor distinto entre normativas de diferentes unidades da federação sobre a mesma realidade hidrográfica. Caso o cenário atual permaneça, a perspectiva ao longo dos anos é cada vez mais a importação de tilápia ao território paraense e cada vez menos adeptos na atividade, uma vez que os custos operacionais exigidos, aliados a uma cadeia produtiva incipiente, não possibilitarão ao produtor local ser competitivo frente a tilápia oriunda de outros estados.

\section{Agradecimentos}

À Coordenação de Aperfeiçoamento de Pessoal de Nível Superior (CAPES) pelo suporte financeiro, bem como aos proprietários das fazendas visitadas pela atenção e disponibilidade de informações, as quais foram essenciais para o desenvolvimento deste trabalho.

\section{Referências}

Ahmed, N.; Young, J. A.; Dey, M. M.; Muir, J. F. From production to consumption: a case study of tilápia marketing systems in Bangladesh. Aquaculture International 20(1), 
51-70, 2012. doi: 10.1007/s10499-011-9441-0

ANA - Agência Nacional de Águas. As 12 Regiões Hidrográficas Brasileiras. Brasília, 2019. Disponível em: $<$ https:// www.ana.gov.br/as-12-regioes-hidrograficas-brasileiras/ links-12-regioes>. Acesso em: dez. 2019.

Attayde, J. L.; Brasil, J.; Menescal, R. A. Impacts of introducing Nile tilapia on the fisheries of a tropical reservoir in North-eastern Brazil. Fisheries Management and Ecology, 18(6), 437-443, 2011. doi: 10.1111/j.13652400.2011.00796.x

Avnimelech, Y. (Org.). Biofloc Technology: a practical guide book. $2^{\mathrm{a}}$ ed. Louisiana: The World Aquaculture Society, 2012. $272 \mathrm{p}$.

Barroso, R. M.; Muñoz, A. E. P.; Cai, J. Social and economic performance of tilapia farming in Brazil. Roma: Fisheries and Aquaculture Circular n ${ }^{\circ} 1181,2019.56$ p.

Bittencourt, L. S.; Leite-Silva; U. R.; Silva, L. M. A.; Tavares-Dias, M. Impact of the invasion from Nile tilapia on natives Cichlidae species in tributary of Amazonas River, Brazil. Biota Amazônia, 4(3), 88-94, 2014. doi: 10.18561/2179-5746/biotaamazonia.v4n3p88-94

Brabo, M. F.; Dias, B. C. B.; Santos, L. D.; Ferreira, L. A.; Veras, G. C.; Chaves, R. A. Competitividade da cadeia produtiva da piscicultura no Nordeste Paraense sob a perspectiva dos extensionistas rurais. Informações Econômicas, 44(5), 5-17, 2014.

Brabo, M. F. Piscicultura no estado do Pará: situação atual e perspectivas. Acta of Fisheries and Aquatic Resources, 2(1), 1-7, 2014.

Brabo, M. F.; Costa, M. W. M.; Paixão, D. J. M. R.; Costa, P. W. J.; Veras, C. G. Potencial invasor de tilápia (Oreochromis niloticus) em microbacias hidrográficas do Nordeste paraense, Amazônia, Brasil. Magistra, 27(2), 227-234, 2015.

Brabo, M. F.; França, F. A.; Paixão, D. J. M. R.; Costa, M. W. M.; Campelo, D. A. V. Veras, G. C. Avaliação econômica da produção de espécies alternativas à tilápia em pisciculturas no nordeste paraense. Informações Econômicas, 46(2), 16-23, $2016 \mathrm{a}$.

Brabo, M. F.; Pereira, L. F. S.; Costa, J. W. P.; Campelo, D. A. V.; Veras, G. C. A. Cenário atual da produção de pescado no mundo, no Brasil e no estado do Pará: ênfase na aquicultura. Acta of Fisheries and Aquatic Resources, 4(2), 50-58, 2016b. doi: 10.2312/ActaFish.2016.4.2.50-58.

Brabo, M. F.; Pereira, L. F. S.; Ferreira, L. A.; Costa, J. W. P.; Campelo, D. A. V.; Veras, G. C. A cadeia produtiva da aquicultura no nordeste paraense, Amazônia, Brasil. Informações Econômicas, 46(4), 16-26, $2016 \mathrm{c}$.

Brabo, M. F.; Ferreira, L. A.; Veras, G. C. Aspectos históricos do desenvolvimento da piscicultura no Nordeste paraense: trajetória do protagonismo a estagnação. Revista em Agronegócio e Meio Ambiente, 9(3), 595-615, 2016d. doi: http://dx.doi.org/10.17765/2176-9168.2016v9n3p595-615

Brabo, M. F.; Paixão, D. J. M. R.; Mesquita, R, L.; Costa, M. W. M.; Campelo, D. A. V.; Veras, G. C. Viabilidade econômica da criação de tilápia em tanques-rede no Nordeste paraense, Amazônia, Brasil. Custose @gronegócio on line, 13, Edição Especial, 284-303, 2017.

Brabo, M. F.; Matos, S. C. N; Serra, R. H. P. F.; Costa, B. G. B.; Campelo, D. A. V.; VERAS, G. C. A tilapicultura no estado do Pará, Amazônia. Informações Econômicas, 50, 1-11, 2020.

Brasil. Decreto Federal no 2.519 de 16 de março de 1998. Promulga a Convenção sobre Diversidade Biológica, assinada no Rio de Janeiro, em 05 de junho de 1992. Brasília: DOU de 16/03/1998a.

Brasil. Portaria do IBAMA n 145 de 29 de outubro 1998. Estabelece normas para a introdução, reintrodução e transferência de peixes, crustáceos, moluscos e macrófitas aquáticas para fins de aquicultura, excluindo-se as espécies animais ornamentais. Brasília: DOU de 30/10/1998b.

Brasil. Portaria IBAMA $n^{\circ} 27$ de 22 de maio de 2003. Altera a Portaria $n^{\circ} 145$ de 29 de outubro de 1998. Brasília: DOU de 22/05/2003a.

Brasil. Decreto Federal $n^{\circ} 4.895$ de 25 de novembro de 2003. Dispõe sobre a autorização de uso de espaços físicos de corpos d'água de domínio da União para fins de aquicultura, e dá outras providências. Brasília: DOU de $25 / 11 / 2003 b$.

Brasil. Resolução CNRHn ${ }^{\circ}$. 32, de 15 de outubro de 2003. Institui a Divisão Hidrográfica Nacional, em regiões hidro- 
gráficas. Brasília: DOU de 17/12/2003c.

Brasil. Lei $n^{\circ} 11.326$ de 24 de julho de 2006. Estabelece as diretrizes para a formulação da Política Nacional da Agricultura Familiar e Empreendimentos Familiares Rurais. Brasília: DOU de 24/07/2006.

Brasil. Resolução CONAMA $n^{\circ} 413$ de 26 de junho de 2009. Estabelece normas e critérios para o licenciamento ambiental da aquicultura, e dá outras providências. Brasília: DOU de 30/06/2009a.

Brasil. Lei n ${ }^{\circ} 11.959$ de 29 de junho de 2009. Dispõe sobre a Política Nacional de Desenvolvimento Sustentável da Aquicultura e da Pesca, regula as atividades pesqueiras, revoga a Lei no 7.679, de 23 de novembro de 1988, e dispositivos do Decreto-Lei no 221, de 28 de fevereiro de 1967, e dá outras providências. Brasília: DOU de 29/06/2009b.

Brito, T. P.; Santos, A. T. S.; Quintairos, R. R. D.; Costa, L. C. O. Aspectos tecnológicos da piscicultura do município de Capitão Poço, Pará, Brasil. Biota Amazônia, 7(1), 17-25, 2017. Doi: http://dx.doi.org/10.18561/2179-5746

De-Carvalho, L. R. H.; Souza, L. A. R.; Cintra, A. H. I. A aquicultura na microrregião do Guamá, Pará, Amazônia Oriental, Brasil. Revista de Ciências Agrárias, 56(1), 1-6, 2013. doi: http://dx.doi.org/10.4322/rca.2013.009

FAO - Food and Agriculture Organization of the United Nations. Fishery and aquaculture statistics 2017. Roma: FAO yearbook, 2019. 108 p.

Feiden, A.; Ramos, M. J.; Chidichima, A. C.; Schmidt, C. M.; Fiorese, M. L.; Coldebella, A. A cadeia produtiva da tilápia no oeste do Paraná: uma análise sobre a formação de um arranjo produtivo local. Redes, 23(2), 238-263, 2018. doi: 10.17058/redes.v23i2.8992

Furlaneto, F. P. B.; Ayroza, D. M. M. R.; Ayroza, L. M. S. Custo e rentabilidade da produção de tilápia (Oreochromis spp.) em tanque-rede no médio Paranapanema, estado de São Paulo, safra 2004/05. Informações Econômicas, 36(3), 63-69, 2006.

Hasan, T.; Roy, A.; Bhowmik, S.; Hossain, S.; Islam, M. S.; Hossain, A. Studies on Growth and Survival of Hormone Treated and Genetically Converted Mono-Sex Tilapia from Larvae to Juvenile Stage. American journal of biotechnolo- gy and molecular sciences, 5(1), 1-7, 2016. doi: 10.5251/ ajbms.2016.5.1.1.7

IBGE - Instituto Brasileiro de Geografia e Estatística. Banco de dados: informações do estado do Pará. Rio de Janeiro, 2019. Disponível em: <https://cidades.ibge.gov.br/brasil/ pa/panorama>. Acesso em: dez. 2019.

Malterud, K. Theory and interpretation in qualitative studies from general practice: why and how? Scandinavian Journal of Public Health, 44(2), 120-129, 2015. doi: 10.1177/1403494815621181

Maranhão. Portaria SEMA n ${ }^{\circ} 60$ de 29 de abril de 2010. Dispõe sobre a dispensa de Licenciamento Ambiental de empreendimentos de pequeno porte de aquicultores familiares enquadrados no PRONAF. São Luís: DOE de 05/05/2010.

Mato Grosso. Decreto ${ }^{\circ} 1.190$ de 15 de setembro de 2017. Altera e acrescenta dispositivo ao Decreto $\mathrm{n}^{\circ} 8.149$, de 27 de setembro de 2006, e dá outras providências. Cuiabá: DOE de 15/09/2017.

Mato Grosso. Lei $n^{\circ} 10.669$ de 16 de janeiro 2018. Altera e revoga dispositivos da Lei $\mathrm{n}^{\circ} 8.464$, de 04 de abril de 2006, altera dispositivo da Lei $n^{\circ} 9.408$, de 01 de julho de 2010, e dá outras providências. Cuiabá: DOE de 16/01/2018.

Mireku, K. K.; Kassam, D.; Changadeya, W.; Attipoe, F. Y. K. Characterization of the Production and Dissemination Systems of Nile Tilapia in Some Coastal Comm unities in Ghana. Sustainable Agriculture Research, 7(1), 14-24, 2018. doi: https://doi.org/10.5539/sar.v7n1p14

Ngoc, P. T. A.; Meuwissen, M. P. M.; Tru, L. C.; Bosma, R. H.; Verreth, J.; Lansink, A. O. Economic feasibility of recirculating Aquaculture systems in pangasius farming. Aquaculture Economics \& Management, 20(2), 185-200, 2016. doi: http://dx.doi.org/10.1080/13657305.2016.115 6190

O’ de Almeida-Júnior, C. R. M.; Souza, R. A. L. Aquicultura no Nordeste paraense, Amazônia Oriental, Brasil. Boletim Técnico Cientifico do CEPNOR, 13(1), 33-42, 2013. doi: 10.17080/1676-5664/btcc.v13n1p33-42

Oliveira, A. S. C.; Souza, R. A. L.; Melo, N. F. A. C. Estado da Arte da Piscicultura na Mesorregião Sudoeste Paraense - Amazônia Oriental. Boletim Técnico Cientifico do 
CEPNOR, 14(1), 33 - 38, 2014. doi: 10.17080/1676-5664/ btcc.v14n1p33-38

Pará. Lei Estadual $n^{\circ} 6.713$ de 25 de janeiro de 2005. Dispõe sobre a Política Pesqueira e Aquícola no Estado do Pará, regulando as atividades de fomento, desenvolvimento e gestão ambiental dos recursos pesqueiros e da aquicultura e dá outras providências. Belém: DOE de 25/01/2005.

Pará. Decreto Estadual n 2.020 de 24 de janeiro de 2006. Regulamenta a Lei $\mathrm{n}^{\circ} 6.713$, de 25 de janeiro de 2005, que dispõe sobre a Política Pesqueira e Aquícola no Estado do Pará, regulando as atividades de fomento, desenvolvimento e gestão ambiental dos recursos pesqueiros e da aquicultura, e dá outras providências. Belém: DOE de 24/01/2006.

Pará. Instrução Normativa $n^{\circ} 004$ de 10 de maio de 2013. Dispõe sobre a regularização e o licenciamento ambiental de empreendimentos e atividades aquícolas no Estado do Pará e regulamenta o Licenciamento Ambiental Simplificado, com a expedição de Licença Ambiental Simplificada - LAS, bem como trata da possibilidade de dispensa de licenciamento, sem prejuízo de outras exigências estabelecidas na legislação em vigor. Belém: DOE de 10/05/2013.

Pará. Resolução COEMA ñ 143 de 20 de dezembro de 2018. Dispõe sobre diretrizes para o cultivo de espécies exóticas em empreendimentos aquícolas do Estado do Pará, e dá outras providências. Belém: DOE de 20/12/2018.

Paragominas. Lei $n^{\circ} 961$ de 17 de maio de 2018. Dispõe sobre a regularização da criação de espécies exóticas aquícolas em sistema fechado no município de Paragominas e dá outras providências. Paragominas: Câmara Municipal em 17/05/2018.

Paraná. Resolução SEMA $n^{\circ} 7$ de 12 de fevereiro de 2019. Estabelece normas e critérios para o licenciamento ambiental da atividade de aquicultura e Maricultura. Curitiba: DOE de 18/02/2019.

PEIXE-BR - Associação Brasileira da Piscicultura. Anuário Peixe-BR da Piscicultura 2020. São Paulo: Associação Brasileira da Piscicultura, 2020.136 p.

Porto, E. P.; Oliveira, C. A. L.; Martins, E. N.; Ribeiro, R. P.; Conti, A. C. M.; Kunita, N. M.; Oliveira, S. N.; Porto, P. P. Respostas à seleção de características de desempenho em tilápia-do-nilo. Pesquisa Agropecuária Brasileira, 50(9),
745-752, 2015. doi: 10.1590/S0100-204X2015000900002

Rego, M. A. S.; Sabbag, O. J.; Soares, R.; Peixoto, S. Financial viability of inserting the biofloc technology in a marine shrimp Litopenaeus vannamei farm: a case study in the state of Pernambuco, Brazil. Aquaculture International, 25(1), 473-483, 2017. doi: doi:10.1007/s10499-016-0044-7

Santos-Filho, L. G. Vieira-Santos, S. G. A.; Silva, C. E. L. S.; Silva, R. C. A. Utilização de indicadores de viabilidade econômica na produção de tilápia (Oreochromis Niloticus) em sistema de recirculação: estudo de caso de uma piscicultura de pequena escala em Parnaíba-PI. Organizações Rurais \& Agroindustriais, 18(4), 304-314, 2017. doi: 10.21714/2238-68902016v18n4p304

SIDRA - Sistema IBGE de Recuperação Automática. Banco de tabelas estatísticas. Rio de Janeiro, 2019. Disponível em: <https://sidra.ibge.gov.br/home/ipca15/brasil>. Acesso em: dez. 2019.

Silva, A. M. C. B.; Souza, R. A. L.; Melo, Y. P. C.; Zacardi, D. M.; Paiva, R. S.; Nakayama, L. Diagnóstico da piscicultura na mesorregião Sudeste do Estado do Pará. Boletim Técnico Cientifico do Cepnor, 10(1), 55-65, 2010. doi: http:// dx.doi.org/10.32519/tjfas.v10i1.1160

Souza, G. M.; Leite, M. A. Custo de produção de piscicultura da espécie tilápia no sistema intensivo de tanque-rede. Qualia: a ciência em movimento, 2(2), 141-167, 2016.

Tocantins. Resolução COEMA $n^{\circ} 88$ de 05 de dezembro de 2018. Dispõe sobre o Licenciamento Ambiental da Aquicultura no Estado do Tocantins. Palmas: DOE de 07/12/2018.

Tocantins. Grupo norueguês busca incentivos fiscais para instalação de centro de melhoramento genético de Tilápia no Tocantins, 2019a. Disponível em: < https://portal.to.gov. br/noticia/2019/4/8/grupo-noruegues-busca-incentivos-fiscais-para-instalacao-de-centro--de-melhoramento-genetico-de-tilapia-no-tocantins/>. Acesso em: ago. 2020.

Tocantins. Durante lançamento do Tilapiatins, Governo garante $R \$ 200$ milhões em crédito ao aquicultor, 2019b. Disponível em: <https://portal.to.gov.br/noticia/2019/5/8/ durante-lancamento-do-tilapiatins-governo-garante-r-200-milhoes-em-credito-ao-aquicultor/>. Acesso em: ago. 2020 . 
Tocantins. Criação de tilápia em tanques rede pode ser ampliada no Tocantins, 2020. Disponível em: $<$ https:// seagro.to.gov.br/noticia/2020/3/9/criacao-de-tilapia-em-tanques-rede-pode-ser-ampliada-no-tocantins/>. Acesso em: ago. 2020.

Trombeta, T. D.; Bueno, G. W.; Mattos, B. O. Análise econômica da produção de tilápia em viveiros escavados no Distrito Federal, 2016. Informações Econômicas, 47(2), 42-49, 2017.
Viana, J. S.; Farias, L. C. F.; Paixão, D. J. M. R.; Santos, M. A. S.; Souza, R. F. C.; Brabo, M. F. Índice de desempenho competitivo de pisciculturas no estado do Pará, Amazônia, Brasil. Informações Econômicas, 49(3), 19-30, 2018.

Zacardi, D. M.; Lima, M. A. S.; Nascimento, M. M.; Zanetti, C. R. M. Caracterização socioeconômica e produtiva da aquicultura desenvolvida em Santarém, Pará. Acta of Fisheries and Aquatic Resources, 5(3), 102-112, 2017. doi: 10.2312/ActaFish.2017.5.3.102-112 